\title{
Capturing VE-Cadherin-Positive Endothelial Progenitor Cells for in-stent Vascular Repair
}

\author{
Tetsuaki Hirase
}

Department of Bioscience and Genetics, National Cerebral and Cardiovascular Center Research Institute, Suita, Japan

\section{See article vol. 23: 67-80}

Percutaneous coronary intervention using stents have largely contributed to the management of coronary artery diseases. A drug-eluting stent (DES) that releases anti-proliferative agents against vascular cells has decreased the incidence of in-stent restenosis compared with bare metal stent (BMS), although the inhibition of physiological vascular wall repair at stent sites including re-endothelialization by DES causes life-threatening subacute thrombosis that requires anti-coagulation therapy for prevention. Accordingly, DES could be considered to be a double-edged sword ${ }^{1)}$.

DES is composed of a platform, polymer, and drug that play important roles in the development of in-stent restenosis and in the failure of re-endothelialization. As a pioneering and promising approach, endothelial progenitor cell (EPC) capture stents that could promote physiological vascular wall repair at stent sites by recruiting circulating EPCs, which differentiate into mature vascular endothelial cells and accelerate re-endothelialization, into stents using antibodies against cell surface antigens of EPCs have been developed to overcome disadvantages of DES in the last decade. Anti-human CD34 antibody-coating bioengineered stent aiming to recruit circulating CD34positive hematopoietic cells has been developed for clinical use. Despite favorable results in animal studies, clinical studies have revealed that EPC capture stent using anti-CD34 antibody increased in-stent restenosis and thrombosis, which result in increased incidence of cardiac events compared with $\mathrm{DES}^{2)}$. Because CD34-positive hematopoietic cells comprise heterogeneous subsets that differentiate into not only vascular endothelial cells but also vascular smooth

Address for correspondence: Tetsuaki Hirase, Department of Bioscience and Genetics, National Cerebral and Cardiovascular Center Research Institute, Suita, Osaka, Japan

E-mail: hirase@ri.ncvc.go.jp

Received: October 10, 2015

Accepted for publication: October 14, 2015 muscle cells and proinflammatory immune cells, certain subsets captured by anti-CD34 antibody potentially enhance in-stent restenosis. Identification of EPC subsets that differentiate more selectively into vascular endothelial cells using more specific cell surface markers would result in the development of EPC capture stents with enhanced physiological vascular repair at stent sites. Peptides and aptamers capable of specifically binding to EPC markers require testing as alternative and more efficient EPC capture tools instead of antibodies.

Tang et al. demonstrated in this issue of $J$ Atheroscler Thromb that a novel stent composed of zwitterionic polymer coated with anti-VE-cadherin antibody promoted re-endothelialization and reduced in-stent thrombosis and restenosis in an animal model ${ }^{3)}$. VEcadherin is an adhesion molecule that is specifically expressed in vascular endothelial cells and plays crucial roles in the formation and maintenance of endothelial cell-cell communication in developing and mature blood vessels. Among EPC subsets, outgrowth endothelial cells (OECs) that exhibit greater vasculogenic activity with more rapid proliferation and more active migration preferentially express VE-cadherin ${ }^{4,5)}$. Therefore, capturing OECs more selectively with anti-VEcadherin antibody among a range of EPC subsets could be responsible for more efficient re-endothelialization and anti-thrombogenicity of anti-VE-cadherin antibody-coated zwitterionic stent as demonstrated in the present study. Furthermore, the interaction between scaffold polymers of stents and cells that are recruited from circulation or migrate from adjacent vascular wall and then anchor at stent sites regulates cell survival, proliferation, differentiation, and maturation in the process of vascular wall repair after stent implantation $^{6)}$. Accordingly, the characteristics of polymers used for stents have great impact on clinical outcome such as in-stent restenosis and thrombosis. The present study indicates that the zwitterionic polymer was an optimal scaffold for VE-cadherin-positive EPC for anchoring, survival, and proliferation.

Although the concept EPC capture is attractive 
from the perspective of biogenesis utilizing patients' own cells, it has been reported that the quantity and quality of circulating EPCs are altered in patients with coronary artery diseases because of aging, life style including smoking, and metabolic disorders such as diabetes and dyslipidemia ${ }^{7}$. In addition to EPC subset characterization, methods for selective and efficient capture of EPCs and the optimization of cell-polymer interaction, EPC quality derived from patients may be one of the toughest barrier to be overcome to develop anti-VE-cadherin antibody-coated zwitterionic stent, which represented a favorable outcome in vitro and in vivo in the present study, for clinical use in coronary artery diseases.

\section{Conflict of Interests}

None.

\section{References}

1) Romero ME, Yahagi K, Kolodgie FD, Virmani R: Neoatherosclerosis from a pathologist's point of view. Arterioscler Thromb Vasc Biol, 2015; 35: e43-e49
2) Liu W, Peng $Y$, Wu B, Li Q, Chai $H$, Ren $X$, Wang $X$, Zhao Z, Chen M, Huang DJ: A meta-analysis of the impact of EPC capture stent on the clinical outcomes in patients with coronary artery disease. J Interv Cardiol, 2013; 26: 228-238

3) Tang H, Wang Q, Wang X, Zhou J, Zhu M, Qiao T, Liu C, Mao C, Zhou M: Effect of a novel stent on re-endothelialization, platelet adhesion and neointimal formation. J Atheroscler Thromb, 2016; 23: 67-80

4) Hur J, Yoon CH, Kim HS, Choi JH, Kang HJ, Hwang KK, Oh BH, Lee MM, Park YB: Characterization of two types of endothelial progenitor cells and their different contributions to neovasculogenesis. Arterioscler Thromb Vasc Biol, 2004; 24: 288-293

5) Yoder MC, Mead LE, Prater D, Krier TR, Mroueh KN, Li F, Krasich R, Temm CJ, Prchal JT, Ingram DA: Redefining endothelial progenitor cells via clonal analysis and hematopoietic stem/progenitor cell principals. Blood, 2007; 109: 1801-1809

6) Scott RA, Panitch A: Macromolecular approaches to prevent thrombosis and intimal hyperplasia following percutaneous coronary intervention. Biomacromolecules, 2014; 15: 2825-2832

7) Fadini GP, Losordo D, Dimmeler S: Critical reevaluation of endothelial progenitor cell phenotypes for therapeutic and diagnostic use. Circ Res, 2012; 110: 624-637 